\title{
Agent based Particle Swarm Optimization for Load Frequency Control of Distribution Grid
}

Cha, Seung-Tae; Saleem, Arshad; Wu, Qiuwei; Østergaard, Jacob

Published in:

47th Universities Power Engineering Conference, UPEC'2012

Publication date:

2012

Link back to DTU Orbit

Citation (APA):

Cha, S-T., Saleem, A., Wu, Q., \& Østergaard, J. (2012). Agent based Particle Swarm Optimization for Load Frequency Control of Distribution Grid. In 47th Universities Power Engineering Conference, UPEC'2012

\section{General rights}

Copyright and moral rights for the publications made accessible in the public portal are retained by the authors and/or other copyright owners and it is a condition of accessing publications that users recognise and abide by the legal requirements associated with these rights.

- Users may download and print one copy of any publication from the public portal for the purpose of private study or research.

- You may not further distribute the material or use it for any profit-making activity or commercial gain

- You may freely distribute the URL identifying the publication in the public portal

If you believe that this document breaches copyright please contact us providing details, and we will remove access to the work immediately and investigate your claim. 


\section{Agent based Particle Swarm Optimization for Load Frequency Control of Distribution Grid}

\author{
Seung Tae, Cha \\ Technical University of Denmark \\ stc@elektro.dtu.dk
}

\author{
Arshad Saleem \\ Royal Institute of Technology \\ Arshad.Saleem@ics.kth.se
}

\author{
Qiuwei Wu, Jacob Østergaard \\ Technical University of Denmark \\ qw@elektro.dtu.dk \\ joe@elektro.dtu.dk
}

\begin{abstract}
This paper presents a Particle Swarm Optimization (PSO) based on multi-agent controller. Real-time digital simulator (RTDS) is used for modelling the power system, while a PSO based multi-agent LFC algorithm is developed in JAVA for communicating with resource agents and determines the scenario to stabilize the frequency and voltage after the system enters into the islanding operation mode. The proposed algorithm is based on the formulation of an optimization problem using agent based PSO. The modified IEEE 9-bus system is employed to illustrate the performance of the proposed controller via RTDS to verify its practical efficacy. Case studies are presented under different operating conditions.
\end{abstract}

Index Terms-Agent based PSO, Distributed Generation (DG), Islanding Operation, Java, Load Frequency Control, MAS, Microgrid, Optimization, Power System Control, RTDS

\section{INTRODUCTION}

The concept of integrating small-size generation units into low voltage distribution networks as an alternative generating source is gaining popularity, which resulted in large scale deployment of distributed generation (DG) units or high penetration of multiple DG units in power systems. This has certainly brought the concept of the sustainable energy system called Microgrid, where small generating sources located close to load centres are dispersed in the distribution networks as well as controllable loads and several types of intermediate energy storage devices. Microgrids entail the connection of multiple, smaller energy producers to the energy distribution network. Moreover, Microgrids are critical for the adoption of renewable energy sources and can contribute to increasing energy production, efficiency and reliability. The adoption of DG resources or Microgrids can considerably increase reliability of the power system in case of utility outage or when a portion of grid needs to be independent, and can yield a greater amount of flexibility or improved performance. However, it is a challenge to utilize the DGs within distribution networks both efficiently and economically to assist the islanding operation of the distribution networks. A well designed and operated distribution system should cope with changes in the load and system disturbances. It should provide an acceptable high level of power quality in islanding operation while maintaining both frequency and voltage within tolerable limits. In islanded operation mode, the frequency and voltage control of the Microgrid is not straightforward. The main challenge of operating Microgrid in islanding mode is the coordination of DGs in order to control the system frequency and voltages within the islanded systems. A secondary load frequency controller is needed to maintain the system frequency at the desired nominal value. Many efforts have been dedicated to design novel control strategies for Microgrid operation, especially in islanded mode to correctly manage a Microgrid during its transition from a gridconnected to an islanded operation, as well as during its autonomous operation [1][2][3][4]. Recently, different PSO based controllers are commonly used in several literatures as the control strategy for load frequency control [5][6]. PSO is a population-based evolutionary technique that has many key advantages over other optimization techniques, and is not only well suitable for scientific research, but also electric power systems applications. Furthermore, PSO has been proven to be an efficient tool both in terms of speed and optimization capability, and robustness. It is a trend to incorporate the multi-agent technology into power system optimization [7][8][9].

In this paper, a real-time agent based test platform is developed to determine the active power set points of DGs for optimally stabilizing of the system frequency. The modified IEEE 9-bus system has been chosen for demonstrating the feasibility of the proposed agent based PSO method. The system includes three distributed generators, all of which include exciter, stabilizer, speed governor/turbine models. The modified IEEE 9-bus system is modelled in real-time digital simulator (RTDS), while the PSO algorithm based on multi-agent controller is developed in JAVA. The hardware and software setup is illustrated in Fig. 1.

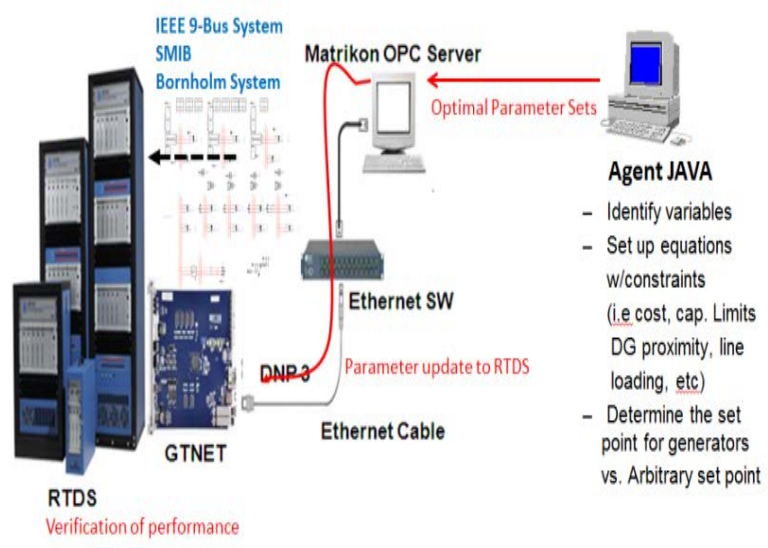

Fig. 1. Hardware \& software setup : RTDS (left) and Java (right) in a complete software in the loop (SIL) environment 
For the control algorithm, agent based PSO, as a member in evolutionary algorithm (EAs), is adopted due to its applicability, speed and optimization capability, and robustness. The algorithm used in this work is based on the previous author's research [10] on improving the efficiency via agent based PSO. The flowchart of the parameter optimization in the agent based PSO is shown in Fig. 2. Three case studies are defined to further find out the optimal tuning of parameters for both steady-state damping and also transient behaviour of the modified IEEE 9-bus system. The entire approach is verified by the Real-Time Digital Simulator (RTDS). Case studies show that the proposed approach can efficiently determining the most economical active power set points for distributed generations subject to islanding operation mode. The various sections in this paper are organized as follows. Section II discusses the key features of particle swarm optimization in general. Modelling of IEEE 9bus system is discussed in Section III. Section IV discusses multi-agent controller using PSO and the scenarios considered for simulations. The simulation results are presented in Section V and concluded in Section VI.

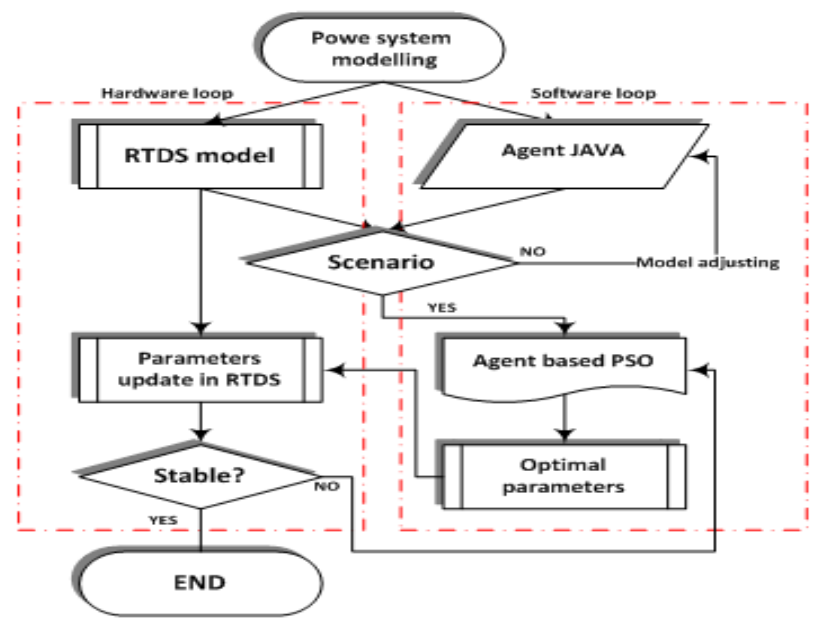

Fig. 2. Flowchart of the parameter optimization in MAS and RTDS verification

\section{OVERVIEW OF PARTIClE SWARM OPTIMIZATION}

The PSO method belongs to the class of swarm intelligence and is therefore a member of wide category of swarm intelligence methods for solving the optimization problems. It is a population based stochastic optimization technique first developed by Dr. Eberhart and Dr. Kennedy in 1995 as a new heuristic method, inspired by social behavior of bird flocking or fish schooling [11]. To find the optimal solution, every bird, or in this case the particle, set the search direction based on two factors, namely previous best experience (the position corresponding to the best fitness as pbest) and the overall best out of all the particles that exist in this population (as gbest) [5][6][12]. PSO model consists of a set of particles is initialized with a population of candidate solutions at random. Particles moving through the search space with a $d$ - dimensional problem to seek new solutions, with fitness, can be calculated as a determined measuring quality. Each particle has a position represented by the vector-position $x_{i}$ ( $i$ is the index of the particle) and speed (velocity) is represented by the vector velocity $v_{i}$. Each particle has so far resulted in the best position (pbest) in vector $x_{i}^{k}$, and the value of the $j$-th dimension is $x_{i j}^{k}$. Vector best position among the swarms so far (gbest) is stored in a vector $x^{l}$, and the value of the $j$-th dimension is $x_{j}^{l}$. During this time of iteration $(t)$, the particles update the speed of the previous speed with the new speed determined by Eq.(1). The new position is determined by the sum of the previous position and the new velocity as shown in Eq. (2). The flowchart of standard PSO algorithm is depicted in Fig. 3. The variables are used in PSO algorithm and their definitions are also given in Table 1.

$$
\begin{gathered}
v_{i j}(t+1)=w v_{i j}(t)+ \\
c_{1} r_{1}\left(x_{i j}^{k}(t)-x_{i j}(t)\right)+c_{2} r_{2}\left(x_{i j}^{l}(t)-x_{i j}(t)\right) \\
x_{i j}(t+1)=x_{i j}(t)+v_{i j}(t+1)
\end{gathered}
$$

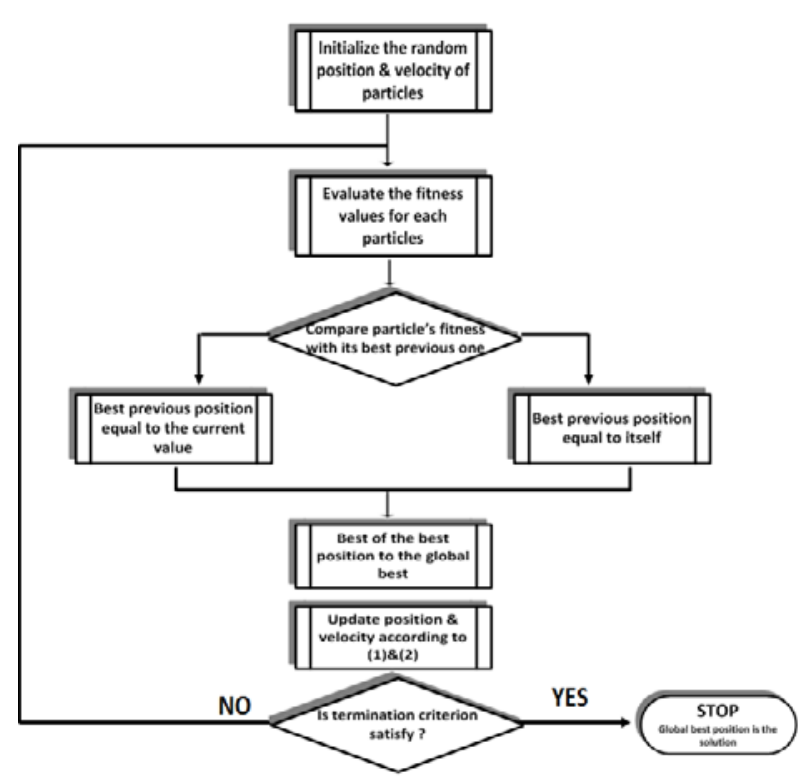

Fig. 3. Flowchart of standard PSO algorithm

TABLE I

VARIABLES USED IN PSO ALGORITHM

\begin{tabular}{|l|l|}
\hline \multicolumn{1}{|c|}{ Variable } & \multicolumn{1}{c|}{ Definition } \\
\hline$x_{i}$ & Position of ith particle \\
\hline$v_{i}$ & Velocity of ith particle \\
\hline pbest & $\begin{array}{l}\text { Best position particle i achieved } \\
\text { based on its own experience }\end{array}$ \\
\hline gbest & $\begin{array}{l}\text { Best particle position based on } \\
\text { overall swarm's experience }\end{array}$ \\
\hline$w$ & Inertia Weight \\
\hline$c_{1} \& c_{2}$ & Two positive coefficients \\
\hline$r_{1} \& r_{2}$ & Randomly generated numbers \\
\hline$k$ & Iteration index \\
\hline
\end{tabular}




\section{Model of IEEE 9 Bus System}

The modified IEEE 9-bus test system is used to illustrate the islanding operation of the distribution power system, and to validate the proposed multi-agent based controller for the islanding operation of the distribution systems. A single line diagram of the modified IEEE 9-bus test system in RSCAD is shown in Fig. 4. The modified IEEE 9-bus system comprises a $60 \mathrm{kV}, 50 \mathrm{~Hz}$ grid which feeds an $11 \mathrm{kV}$ network through a $60 / 11 \mathrm{kV}$ transformer. The system consists of three DG units, eight transmission lines, one transformer and four loads. Three DG units with nominal power of 4.85 MVA are connected to bus 1,3 and bus 4 , respectively, and simulated with 1.5 MW power output before islanding operation. The loads, totaling 6.0 MW, are distributed along the bus 5,6,7,8 and are modeled as constant impedance loads.

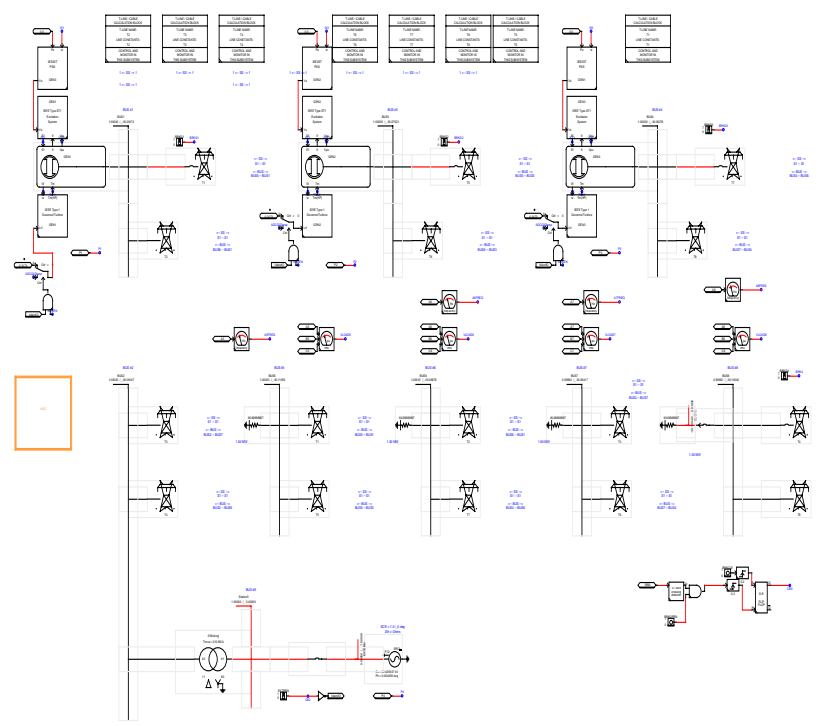

Fig. 4. RTDS implementation of IEEE 9-bus test system

The DG offers an economic opportunity by introducing the combined heat and power (CHP) units, which is currently the most important means of improving energy efficiency [13][14]. The commercial co-generation systems use different types of fuels to drive the steam turbine. The steam turbine couples with the rotor of the synchronous generator to generate electric power, and they are operated according to the heat demand. The transient and sub-transient impedances of the synchronous generator are considered so that more accurate transient stability analysis can be obtained [15]. To regulate the bus voltage of the islanded system, the excitation system, the IEEE standard type ST1 model, is used for the steam turbine cogeneration units. Also, in order to achieve the quick response of the steam turbine mechanical power output to the frequency variation, the IEEEG1 governor model is applied in the speed governing system. For all the simulation cases, when the grid is connected to the $11 \mathrm{kV}$ bus, the DGs are operating in the PQ mode and the voltage and frequency at the $11 \mathrm{kV}$ bus are regulated by the grid. Under the islanding operation mode, the DG units are switched from PQ mode to V-f mode, and the $11 \mathrm{kV}$ bus voltages and the system frequency are then regulated by the Load Frequency Control (LFC) scheme used to control the speed of the DGs. The LFC scheme, as shown in Fig. 5, measures the system frequency and changes load settings of DGs via the LFC signal. All the relevant parameters are given in [10][16].

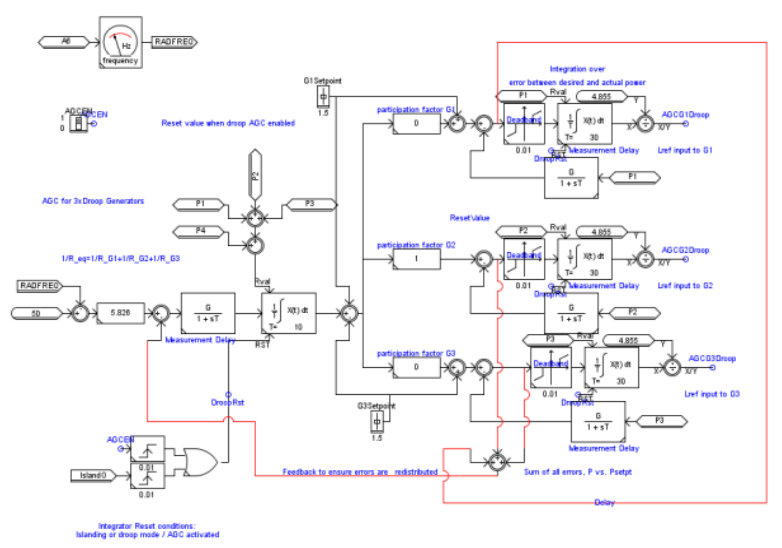

Fig. 5. RTDS model of LFC scheme to control the speed of DGs

\section{Multi Agent Controller Using PSO ALGORITHM}

In this paper, the PSO algorithm searches in parallel using a group of candidate solutions called 'particles' in terms of PSO. A single particle corresponds to a candidate solution to the problem. A particle moves toward the optimum based on its present velocity, its previous experience, and the experience of its neighbors. In an $n$-dimensional search space, the position and velocity of particle are represented as vectors. The position and velocity of individual $i$ are represented as the vectors,

$$
X_{i}=\left(x_{i}, \ldots \ldots . x_{i n}\right) \text { and } V_{i}=\left(v_{i} \ldots \ldots \ldots v_{i n}\right)
$$

Let $P_{\text {besti }}=\left(x_{\text {i1pbest }}, \ldots \ldots x_{\text {inpbest }}\right)$ and $G_{\text {besti }}=$ $\left(x_{\text {igbest }}, \ldots \ldots \ldots x_{\text {ngbest }}\right)$ be the best position of individual $i$ and its neighbors' best position so far, respectively.

Using the information, the updated velocity of individual $i$ is modified under the following equation in the PSO algorithm:

$$
V_{i k}+1=w V_{i k}+c_{1} r_{1} \mathrm{x}\left(P_{\text {bestik }}-X_{i k}\right)+c_{2} r_{2} \mathrm{x}\left(G_{\text {bestik }}-X_{i k}\right)
$$

Where,

$V_{i k}$ : velocity of individual $i$ at iteration $k$,

$\omega$ : inertia weight parameter

$c_{1}, c_{2}$ : acceleration coefficients

$r_{1}, r_{2}$ : random numbers generated between 0 and 1

$X_{i k}$ : position of individual $i$ at iteration $k$,

$P_{\text {bestik }}$ : best position of individual $i$ until iteration $k$,

$G_{b e s t i k}$ : best position of the group until iteration $k$. 
In this velocity updating process, the values of parameters such as $\omega, c 1$ and $c 2$ should be determined in advance. In general, the weight $\omega$ is set according to the following Eq. (3) :

$$
\omega=\omega_{\max }-\left(\omega_{\max }-\omega_{\min }\right) \times \text { iter/Itermax }
$$

where,

$\omega_{\max }, \omega_{\min }$ : initial and final weights,

Itermax : maximum number of iteration

Based upon formulation above our objective function is to minimize the cost of providing regulation power from DGs $\left(D G_{i 1} \ldots . . i_{n}\right)$ in the islanded part of the network. For this purpose in first phase the PSO algorithm will attempt to optimize the active and reactive power contribution from each DG. The algorithm will start with a randomly selected value and traverse through a swarm of candidate solutions. Every particle in the swarm will update its best position. Note that in our case PSO algorithm will perform a multi-level optimization i.e., it will attempt to optimize for a number of DGs the values in two dimensions of $\mathrm{P}$ and $\mathrm{Q}$. For future studies, we also plan to extend for third dimension of load conditions.

The objective function in our case would be to find regulation function of the regulation constant of the system for where $K_{i}$ is individual regulation contribution from a single DG in the network.

$$
X_{i k}\left(K_{i 1}\left(p_{i}, q_{i}\right), K_{i 2}\left(p_{i}, q_{i}\right), \ldots \ldots . . K_{\text {in }}\left(p_{i}, q_{i}\right)\right)(4)
$$

The PSO algorithm should search on two levels and three 2 -dimensional search space. In our intended system regulation contribution parameter $K_{i}$ is optimized according to load and system conditions. The PSO algorithm generates the optimal location and the optimal values of the controller parameters simultaneously by minimizing the objective function above. With the optimized parameters based on PSO algorithm, the proposed load frequency controller can effectively achieve the islanding operation.

TABLE II

PARAMETERS USED FOR PSO ALGORITHM

\begin{tabular}{|l|c|}
\hline PSO parameters & Value / Type \\
\hline Swarm size & 12 \\
\hline No. of generations & 16 \\
\hline$w_{\text {start }}, w_{\text {end }}$ & $0.4,0.9$ \\
\hline$c_{1} \& c_{2}$ & 3,3 \\
\hline$r_{1} \& r_{2}$ & $0.4,0.6$ \\
\hline
\end{tabular}

TABLE III

OPTIMIZED PARAMETERS

\begin{tabular}{|c|c|}
\hline Parameters & $\boldsymbol{K}_{\boldsymbol{i}}$ \\
\hline Value & 0.75 \\
\hline
\end{tabular}

\section{REAL Time Simulation RESUlts}

In order to further assess the effectiveness and robustness of the proposed agent based PSO multi-agent LFC, simulation studies are carried out for different fault disturbances. The behavior of the proposed controller under transient conditions is verified. Initially, the test system is balanced and all voltages at the nodes of all loads are at $1 \mathrm{pu}$. Load agents at each load are continuously monitoring the voltage $\&$ frequency to respond to any disturbance. A 3-phase fault is applied at the nominal operating conditions $\left(P_{s c r}=\right.$ $1 p u, \delta_{0}=0$, initial power flow of $1.5 \mathrm{MW}$ ) at $t=9 \mathrm{~s}$. The following cases are considered.

\section{A. Case I : One DG providing LFC}

In this case, only one DG is providing regulation service as defined by the Eq. (5).

$$
f_{t r}=\sum A_{i}(\beta)=R_{\text {svr }}
$$

The corresponding DG provides an extra active power for balancing in the islanded part of the network. The execution sequence is described as follows;

- Step1. Loss of 1.5 MW power from the grid due to an outage or intentional islanding

- $\quad$ Step2. Created an imbalance in the islanded part of the network

- $\quad$ Step3. Load agents observe voltage \& frequency drop

- Step4. Load agents contact DF agent for any available regulation service

- Step5. DF agents informs the current service availability and provides its reference

- Step6. Load agents request DG \#2 agent for provision of service

- $\quad$ Step7. DG \#2 agent accepts the request and provides the service by increasing its active power set point

- $\quad$ Step 8. Voltage \& frequency recover at the nodes of all loads

In the Fig. 6, the response without control (no control, has a steady-state error) is shown with legend LFCOFF (green line) and the response with proposed PSO optimized is shown with legend LFCON (blue line), respectively. The control strategy is to use one DG as the master controller while the other remains as the slaves. The master DG is switched on to V-f mode after islanding to control the overall island voltage and frequency while the other slave DGs are maintained at fixed generation (i.e 1.5 MW). As it can be seen from Fig. 7 that the frequency dropped to $49.45 \mathrm{~Hz}$ and then recovered by the activation of load frequency control scheme. Similarly, the voltage dropped to $0.8728 \mathrm{pu}$ and recovered to the operational range after $77 \mathrm{~s}$ and settled again at $1 \mathrm{pu}$. The response of active and reactive power output of DG\#2 is shown in Fig. 8. 
The master controller is capable of reducing the voltage and frequency excursions considerably and keeping them within permissible limits.

In this case, the load-frequency control scheme was implemented which calls the RTDS dynamic simulation computation module. This computation module runs dynamic simulations for a given controller sample time intervals. At the end of each dynamic simulation, the integral and absolute value of frequency deviation is read from RTDS's output file. Using this information, new power set points are computed and stored in the RTDS's information file for the next dynamic simulation. This process is repeated up to frequency stabilization or a maximum simulation time.

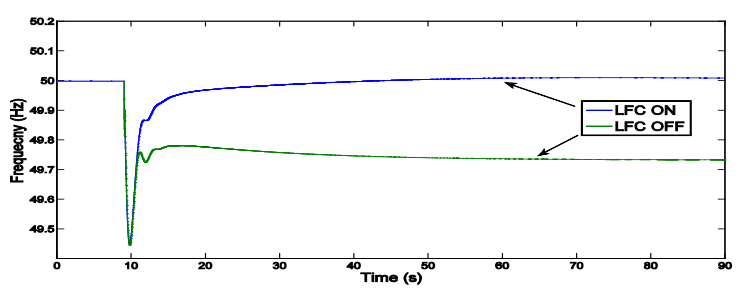

Fig. 6. Comparison between LFC On and Off
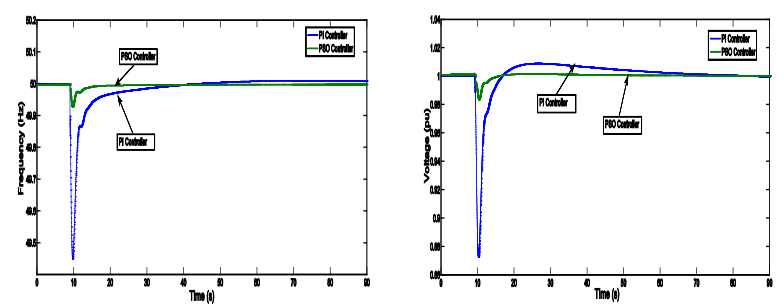

Fig. 7. Monitored changes in frequency waveforms and voltage at bus 5
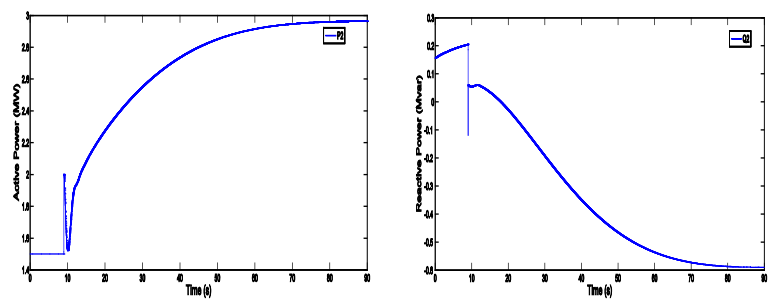

Fig. 8. Monitored active \& reactive power output of DG\#2

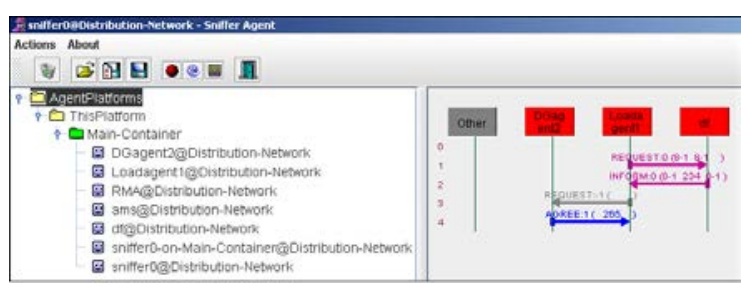

Fig. 9. Agent communication in case I

Fig. 9 shows the communication of agents during the simulation. It can be seen that the load agent sends a request message to the DF agent for regulation service. The DF agent sends back a message with the available service information. Load agent sends a request message to DG agent for provision of this service. The content of request is the amount of active power to be increased. Finally, DG \#2 agent replies with an 'agree' message.

\section{B. Case II : Three DGs providing LFC}

In this case, all three DG units are providing regulation services. The DG units provide an extra active power if required for balancing in the islanded part of the network by sharing or rescheduling between three units based on the participation factors. A 3-phase fault is applied at the nominal operating conditions $\left(P_{s c r}=1 p u, \delta_{0}=0\right)$ at $t=9 \mathrm{~s}$. The system response under this disturbance is shown in Fig. 10. In the Fig. 10, the stability of the system is maintained and the proposed controller can effectively stabilize the frequency and voltages of the system after switching to islanding operation. The control strategy is to use all three DGs as the master controller. The master DGs are switched to V-f mode after islanding to control the overall island voltage and frequency.
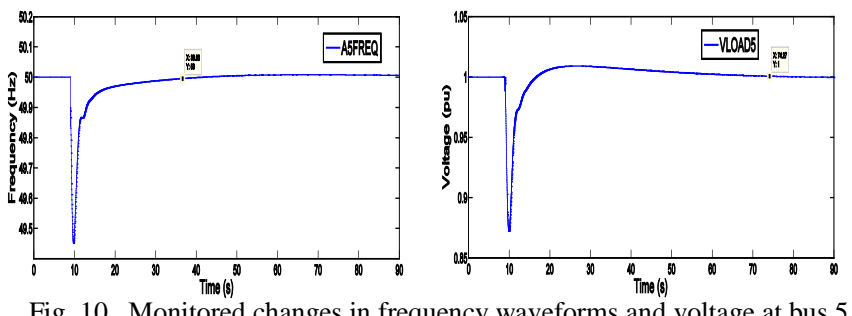

Fig. 10. Monitored changes in frequency waveforms and voltage at bus 5
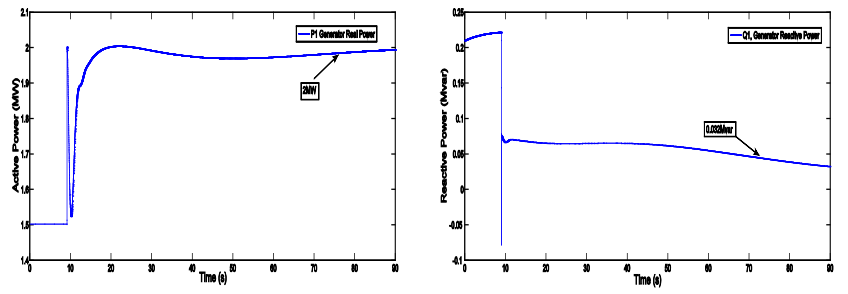

Fig. 11. Monitored active \& reactive power output of DG\#1

As it can be seen from Fig. 10 that the frequency dropped to $49.45 \mathrm{~Hz}$ and then recovered by the activation of load frequency control scheme. Similarly, the voltage dropped to $0.8722 \mathrm{pu}$ and recovered to the operational range after $74 \mathrm{~s}$ and settled again at $1 \mathrm{pu}$.

The controller adjusted the power output of DG \#1 - DG \#3 to desired values and the required power needed (2MW for each DGs) is supplied by all three DG units as shown in Fig. 11. Under the islanding mode, the imbalance is shared by all three DGs. It is clear from the Fig. 10 that all three master controllers are capable of reducing the voltage and frequency excursions considerably, and keeping them within permissible limits.

The communication of agents during the simulation can be omitted because of space limitations.

\section{Case III : Load Shedding}

In this case, it was investigated to use load shedding under islanding operation. These results show that the power balance in the island created by disconnection from the main grid can be maintained by load shedding. Under normal operating conditions, the generation and load are balanced 
and the generator terminal voltages are 1pu. Initially, the system is running in normal condition. A 3-phase fault is applied on the utility side at $t=9 \mathrm{~s}$. This isolation creates an island with 25\% imbalance. As it can be seen from Fig. 12 shows that the voltage dropped to $0.99 \mathrm{pu}$ and the frequency dropped to $49.96 \mathrm{~Hz}$. The load shedding strategy shed the first load encountered, i.e. load 8. After the system sheds the load, it restores the frequency and voltages when the power balance is restored. This is the case where none of DG units are ready to provide regulation service when a part of distribution network is islanded from the main grid. Load agents are informed about unavailability of any regulation service by DF agent. Load agent informs this situation to the load shedding agent. Load shedding agent to shed 1.5 MW in order to achieve balance.
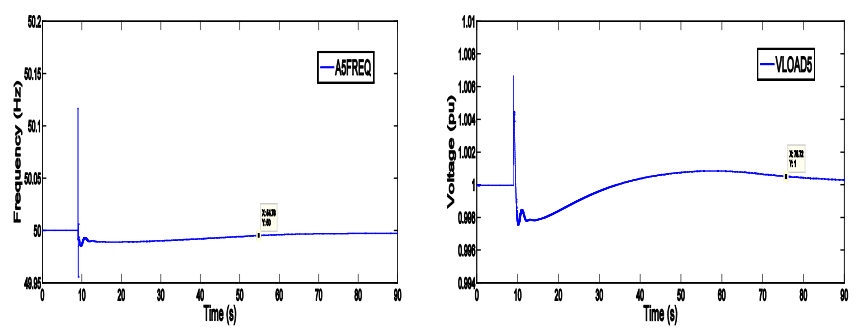

Fig. 12. Monitored changes in frequency waveforms and voltage at bus 5

The control agent detects the fault and informs the load agent \& the DF agent, both of which exchange information and determine the amount of loads to be shed and the amount of power to be produced internally in order to stabilize the grid after islanding. Depending on the pre-defined load priority set by user and the available internal generation, the loading shedding agent can disconnect non-critical loads and certain critical loads. Thus, the load shedding agent disconnects the non-critical loads of 1.5 MW and leaves the critical load intact. All agent actions from detecting the fault (not accounted into the simulation), disconnecting the main circuit breaker, disconnecting the non-critical loads to stabilize the grid can be accomplished. Also, the communication of agents during the simulation can be omitted because of space limitations.

\section{CONCLUSION}

An agent based PSO for load frequency control of islanding operation of the distribution systems has been proposed to help stabilize frequency and voltages of the distribution systems. The case study results with the modified IEEE 9-bus system show that the proposed PSO based LFC in the multi-agent community can respond to the islanding situation of the distribution systems very fast and efficiently stabilize the frequency and voltages of the distribution systems. A real-time digital simulation of the system is carried out and optimization of the parameters of the LFC is achieved in a simple manner through the effective application of PSO algorithm. Hence, the results indicate the efficiency of PSO algorithm for real-time applications and its suitability under varying conditions. However, there are a number of challenges, specific to the proposed PSO based multi-agent control scheme that requires further investigation as future work. These are concerned with multi-set of DG units and loads, coordination strategies, the scalability, and improvement on software in the loop (SIL) optimization using agent java in real-time simulation environment.

\section{ACKNOWLEDGEMENTS}

The work was supported by the Transmission System Operator (TSO), Energinet.dk, the Distribution System Operator (DSO), Østkraft, Bornholm and Technical University of Denmark (DTU).

\section{REFERENCES}

[1] A. Madureira, "Secondary load frequency control for microgrids in islanded operation”, in Proc. International Conference on Renewable Energy and Power Quality, ICREPQ 2005.

[2] J. Y. Kim, J. H. Jeon, "Cooperative control strategy of energy storage system and microsources for stabilizing the microgrid during islanded operation," IEEE Transactions on Power Electronics, vol. 25 no. 12, 2010, pp. 3038-3048.

[3] S. Conti, A. M. Greco, "Generators control systems in intentionally islanded MV microgrids,” in Proc. International Symposium on Power Electronics, Electrical Drives, Automation \& Motion, 2008, pp. 399405.

[4] J. Pecas Lopes, "Large scale integration of micro generation to low voltage grids” ENK5-CT-2002 project.

[5] Muhamad Haddin, Soebagio, Adi Soeprijanto, "Gain coordination of AVR-PSS and AGC based on particle swarm optimization to improve the dynamic stability of the power system," International Journal of Academic Research, vol. 3, no. 3, 2011, pp. 462-470.

[6] A. Soundarrajan, S. Sumathi, C. Sundar, "Particle swarm optimization based LFC and AVR of autonomous power generating system," IAENG International Journal of Computer Science, vol. 37, no. 1, 2010, pp. 371-10 online publication.

[7] M. R. AlRashidi, M. E. El-Hawary, "A survey of particle swarm optimization applications in electric power systems," IEEE Transactions on Evolutionary Computation, vol. 13, no. 4, 2009, pp. 913-918.

[8] S. Shangxiong, "A particle swarm optimization algorithm based on multi-agent system," in Proc. International Conference on Intelligent Computation Technology \& Automation, 2008, pp. 802-805.

[9] M. A. Mazurowski, J. M. Zurada, "Solving multi-agent control problems using particle swarm optimization,” IEEE Swarm Intelligence Symposium, 2007, pp. 1-7.

[10] Seung Tae, Cha, Arshad Saleem, Qiuwei Wu, Jacob Østergaard, "Multi-agent based controller for islanding operation of active distribution networks with distributed generation," in Proc. International Conference on Electric Utility Deregulation and Restructuring and Power Technologies, 2011, pp. 803-810.

[11] Eberhart, R. and Kennedy, "Particle swarm optimization," IEEE International Conference on Neural Networks, vol. IV, 1995, pp. 19421948.

[12] PSO Tutorial, http://www.swarmintelligence.org/tutorials.php..

[13] Venkataramanan G., Chris Marnay, "A large role for microgrids : Are microgrids a viable paradigm for electricity supply expansion,” IEEE Power Energy Magazine, 2008, pp. 78-82.

[14] Marnay C., H. Asano, S. Papathanassio, G. Strbac, "Policy making for microgrids : economic and regulatory issues of microgrid implementation,” IEEE Power Energy Magazine, 2008, pp. 66-77.

[15] P. M. Anderson, A. A. Fouad, "Power system control and stability," Iowa State University Press, Iowa 1977.

[16] Seung Tae, Cha, Qiuwei Wu, Jacob Østergaard "Frequency stabilizing control scheme for a Danish island grid,” in Proc. IEEE Innovative Smart Grid Technologies, 2012, under review. 